\title{
Schistosoma mansoni antigens alter the cytokine response in vitro during cutaneous leishmaniasis
}

\author{
Aline Michelle Barbosa Bafica ${ }^{1 /+}$, Luciana Santos Cardoso ${ }^{1,2}$, Sérgio Costa Oliveira ${ }^{3}$, \\ Alex Loukas ${ }^{4}$, Giuseppe Tittoni Varela1, Ricardo Riccio Oliveira1 , Olívia Bacellar ${ }^{1,5}$, \\ Edgar Marcelino Carvalho, ${ }^{1,5,6}$, Maria IIma Araújo ${ }^{1,5,6}$
}

\footnotetext{
${ }^{1}$ Serviço de Imunologia, Hospital Universitário Professor Edgard Santos, Universidade Federal da Bahia, Rua João das Botas s/n, 40110-160 Salvador, BA, Brasil ²Departamento de Ciências da Vida, Universidade do Estado da Bahia, Salvador, BA, Brasil ${ }^{3}$ Departamento de Bioquímica e Imunologia, Instituto de Ciências Biológicas, Universidade Federal de Minas Gerais, Belo Horizonte, MG, Brasil ${ }^{4}$ Center for Immunity, Infection and Evolution, University of Edinburgh, Edinburgh, UK ${ }^{5}$ Instituto Nacional de Ciência e Tecnologia em Doenças Tropicais ${ }^{6}$ Escola Bahiana de Medicina e Saúde Pública, Salvador, BA, Brasil
}

Schistosoma mansoni infection or associated products are able to down-modulate the type $1 \mathrm{CD} 4^{+} \mathrm{T}$ cell inflammatory response characteristic of autoimmune diseases. In this study, we evaluated how $\mathrm{S}$. mansoni antigens altered the immune response that was induced by the soluble Leishmania antigen (SLA) from cutaneous leishmaniasis (CL) patients. Cytokines were measured from the supernatants of peripheral blood mononuclear cell cultures stimulated with SLA. This was performed using the sandwich enzyme linked immunosorbent assay technique in the presence or absence of S. mansoni recombinant antigens Sm29, SmTSP-2 and PIII. The addition of S. mansoni antigens to the cultures resulted in the reduction of interferon gamma (IFN- $\gamma$ ) levels in $37-50 \%$ of patients. Although to a lesser extent, the antigens were also able to decrease the production of tumour necrosis factor-alpha (TNF- $\alpha$ ). We compared patients that either had or did not have reduction in IFN- $\gamma$ and TNF- $\alpha$ production in cultures stimulated with SLA in the presence of $\mathrm{S}$. mansoni antigens. We found that there was no significant difference in the levels of interleukin (IL)-10 and IL-5 in response to S. mansoni antigens between the groups. The antigens used in this study down-modulated the in vitro proinflammatory response induced by SLA in a group of CL patients through a currently undefined mechanism.

Key words: cutaneous leishmaniasis - S. mansoni antigens - Sm29 - SmTSP-2 - PIII

Leishmaniasis is an infectious disease caused by a protozoan from the genus Leishmania spp. It is one of the most common infectious diseases, affecting 12 million people worldwide with an incidence of 1.5 million cases per year (Desjeux 2001). Four different forms of tegumentary leishmaniasis are described: cutaneous, mucosal, diffuse and disseminated leishmaniasis. Cutaneous leishmaniasis (CL) is the most common clinical manifestation, characterised by one to several skin lesions in exposed areas, with an absence or small number of parasites (Jones et al. 1987, Bogdan et al. 1996).

$\mathrm{CL}$ is endemic in many regions of Central and South America (Jones et al. 1987). In the state of Bahia (BA), in Brazil, the number of CL cases reaches 23.4 per 100,000 inhabitants (SVS/MS 2010).

Some evidence has suggested that the immune response contributes to the tissue injury characteristic of CL. Leishmania donovani infection is controlled by type $1 \mathrm{CD}^{+} \mathrm{T}$ cell (Th1) immune response. The Th1 response is important to produce interferon-gamma (IFN- $\gamma$ ) and activate tissue macrophages (Murray \& Cartelli 1983,

Financial support: $\mathrm{MCT} / \mathrm{CNPq}$ (479417/2008 3 universal) MIA, SCO and EMC are investigators supported by CNPq. + Corresponding author: alinebafica@gmail.com

Received 27 April 2011

Accepted 8 July 2011
Murray et al. 1983). However in the presence of a strong of a Th1 response, there is an increased production of IFN- $\gamma$ and tumour necrosis factor-alpha (TNF- $\alpha$ ). This increased production of inflammatory cytokines leads to intense tissue damage resulting in the development of $\mathrm{CL}$ and mucosal leishmaniasis (Ribeiro-de-Jesus et al. 1998).

Bacellar et al. (2002) showed that mononuclear cells from mucosal leishmaniasis patients have a decreased ability to produce and to respond to interleukin (IL)-10 after restimulation with Leishmania braziliensis antigen in vitro. Moreover, neutralisation of IL-10 enhanced IFN- $\gamma$ production by peripheral blood mononuclear cells (PBMC) and also increased lymphocyte proliferation in patients with CL (Rocha et al. 1999). The regulatory cytokine IL-10 seems to play a major role in modulating the inflammatory responses associated with CL development. However, this cytokine maintains latency in murine models of Leishmania major infection (Belkaid et al. 2001).

In recent years, studies have demonstrated that helminth infections or products from their infections have the potential to modulate Th2-immune responses that result in the pathology of allergic diseases (Araujo et al. 2000, 2004, Cooper et al. 2003). Our research group has demonstrated that asthmatic patients who are infected with Schistosoma mansoni have a less severe course of asthma and an inhibition of the Th2 inflammatory response that seems to be mediated by IL-10 (Medeiros et al. 2004, Cardoso et al. 2006). In a murine model of ovalbumin (OVA)-induced airway inflammation, $S$. 
mansoni antigens reduced the allergic $\mathrm{Th} 2$ response (Cardoso et al. 2010). Other recent experimental studies have shown that $S$. mansoni infection or parasite products induce regulatory cells and cytokines that are able to prevent an autoimmune Th1 inflammatory response seen in diseases such as type-I diabetes, encephalomyelitis and psoriasis (Cooke et al. 1999, Sewell et al. 2003, Atochina \& Harn 2006).

Considering the demonstrated ability of S. mansoni antigens to prevent some Th1-mediated diseases, this study aimed to evaluate the effects of $S$. mansoni antigens on the immune response induced by the soluble Leishmania antigen (SLA) in CL patients. We examined IFN- $\gamma$, TNF- $\alpha$, IL-10 and IL-5 production by PBMC stimulated in vitro with SLA in the presence or absence of the S. mansoni antigens Sm29, tetraspanin 2 (SmTSP-2) and PIII, a fraction of $S$. mansoni soluble adult worm antigen (SWAP).

\section{PATIENTS, MATERIALS AND METHODS}

This study evaluated the ability of $S$. mansoni antigens to alter cytokine production by PBMC from patients with $\mathrm{CL}$, which was assessed based on the PBMC cytokine response to SLA in vitro. The study included 22 individuals living in the endemic area of Corte de Pedra, BA. They attended the local healthcare facility from September 2009-October 2010 and agreed to participate in this study.

All patients included in the study donated blood for PBMC cultures, which were stimulated with SLA in the presence or absence of $S$. mansoni antigens.

S. mansoni antigens - The antigens used in this study included the recombinant proteins Sm29 and SmTSP-2 and a fraction of S. mansoni SWAP obtained by anionic chromatography referred to in this study as PIII. The recombinant proteins were cloned in Escherichia coli. They were tested for lipopolysaccharide (LPS) contamination using a commercially available Chromogenic LAL Kit (Cambrex). The levels of LPS in Sm29 and SmTSP-2 were below $0.25 \mathrm{ng} / \mathrm{mL}$. In order to neutralize the potential effects of LPS, polymyxin B was added to the cell cultures every $12 \mathrm{~h}$ as previously performed (Cardoso et al. 2007).

PBMC cultures and cytokine measurements - PBMCs were obtained using a Ficoll-Hypaque gradient. PBMCs were cultured at a concentration of $3 \times 10^{6}$ cells $/ \mathrm{mL}$ in Roswell Park Memorial Institute 1640 containing 10\% normal human serum $\left(\mathrm{AB}^{+}\right.$, heat inactivated), $100 \mathrm{U} / \mathrm{mL}$ penicillin, $100 \mathrm{mg} / \mathrm{mL}$ streptomycin, $2 \mathrm{mM} \mathrm{L}$-glutamine and $30 \mathrm{mM}$ HEPES (Life Technologies Gibco-BRL, Gaithersburg, MD). Cells were cultured with the antigens Sm29, SmTSP-2 and PIII at a concentration of $5 \mu \mathrm{g} /$ $\mathrm{mL}$ in the presence or absence of SLA $(5 \mu \mathrm{g} / \mathrm{mL})$. The levels of IFN- $\gamma$, TNF- $\alpha$, IL-10 and IL- 5 were measured in the supernatants of PBMC cultures as determined by sandwich enzyme linked immunosorbent assay. The results are expressed as picograms per millilitre $(\mathrm{pg} / \mathrm{mL})$ based on a standard curve.

Statistical analyses - Statistics were analysed utilising the software Statistical Package for Social Science version 9.0 for Windows. Statistical differences between the means of cytokine levels were analysed using Wilcoxon matched pairs test or Mann-Whitney test, as indicated. Fisher's exact test was used to compare proportions. Statistical significance was established at the 95\% confidence interval.

The Ethical Committee of Climério de Oliveira Maternity, Federal University of Bahia, approved the present study. Informed consent was obtained from all study participants or their legal guardians.

\section{RESULTS}

The demographic information for CL patients included in the study is shown in Table I. A total of 22 patients with CL were enrolled in this study: 13 were male and nine were female, with a mean age of $26.2 \pm 9.8$ years (range 6-48 years) (Table I). The majority of patients presented with a single lesion $(77.3 \%)$ and the median lesions size was $100 \mathrm{~mm}^{2}$ (interquartile range, 35.0-276.0).

To test the ability of $S$. mansoni antigens, Sm29, SmTSP-2 and PIII, to down-modulate IFN- $\gamma$ and TNF- $\alpha$ production, these antigens were added into SLA-stimulated PBMC cultures from CL patients. There were no significant differences between the mean levels of IFN- $\gamma$ detected in supernatants of PBMC cultures stimulated with SLA alone [mean \pm standard error $(\mathrm{SEM})=3,568$ $\pm 1,184 \mathrm{pg} / \mathrm{mL}]$ or SLA plus $S$. mansoni antigens $\mathrm{rSm} 29$, SmTSP-2 and PIII $(3,819 \pm 1,144 \mathrm{pg} / \mathrm{mL}, 4,822 \pm 1,373$ $\mathrm{pg} / \mathrm{mL}$ and $3,466 \pm 308.5 \mathrm{pg} / \mathrm{mL}$, respectively) (Fig. $1 \mathrm{~A}-\mathrm{C}$ ). Likewise, no difference was observed in levels of TNF- $\alpha$ in the supernatants of PBMC cultures stimulated with SLA alone $(2,314 \pm 318.5 \mathrm{pg} / \mathrm{mL})$ and SLA plus S. mansoni antigens Sm29, SmTSP-2 and PIII $(2,638 \pm$ $325.5 \mathrm{pg} / \mathrm{mL}, 2,314 \pm 381.5 \mathrm{pg} / \mathrm{mL}$ and 2,167 $\pm 304.4 \mathrm{pg} /$ $\mathrm{mL}$, respectively) (Fig. 1A-C).

A significant increase in the concentration of IL10 was observed when $\operatorname{Sm} 29$ was added to the cultures (mean \pm SEM $=528.8 \pm 151.8 \mathrm{pg} / \mathrm{mL}$ ) as compared to SLA alone $(170.3 \pm 70.7 \mathrm{pg} / \mathrm{mL}, \mathrm{p}<0.0005)$. The difference in mean levels of IL-10 was not significant for the two other $S$. mansoni antigens used in this study SmTSP-2 and PIII (175.2 $\pm 64.6 \mathrm{pg} / \mathrm{mL}$ and $172.6 \pm 53.4$ $\mathrm{pg} / \mathrm{mL}$, respectively) (Fig. 1D-F).

\section{TABLE I}

Demographic characteristics of the cutaneous leishmaniasis patients included in the study

\begin{tabular}{lc}
\multicolumn{1}{c}{$\begin{array}{c}\text { Characteristics } \\
(\mathrm{n}=22)\end{array}$} & Values \\
\hline Age (years) (mean $\pm \mathrm{SD})$ & $26.2 \pm 9.8$ \\
Sex (female/male) & $9 / 13$ \\
Lesions [n (\%)] & $17(77.3)$ \\
1 & $5(22.7)$ \\
$\geq 2$ & $100(35-276)$ \\
Size of lesion [median $\left.\mathrm{mm}^{2}(\mathrm{IQR})\right]$ & \\
\hline
\end{tabular}

IQR: interquatile range; SD: standard deviation. 
A

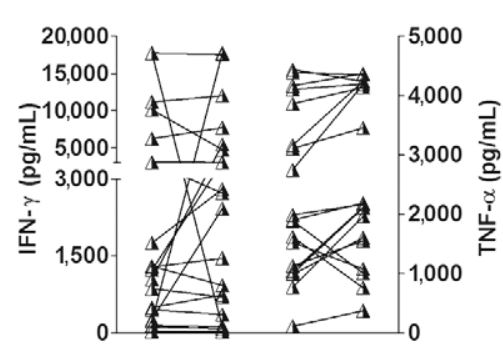

D

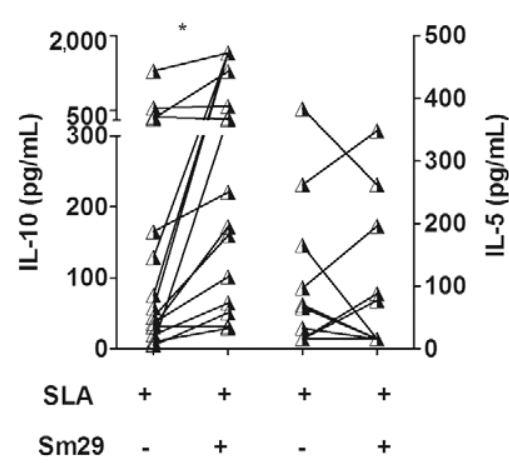

B

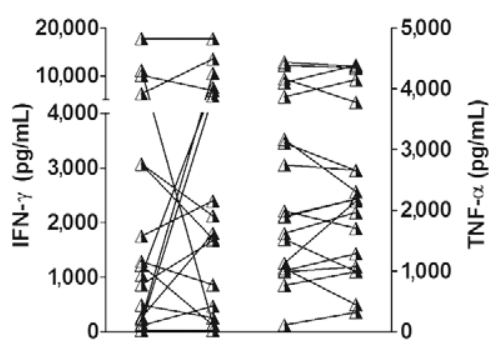

$E$

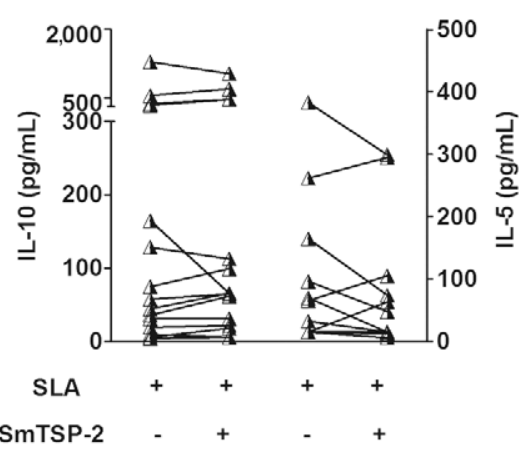

C

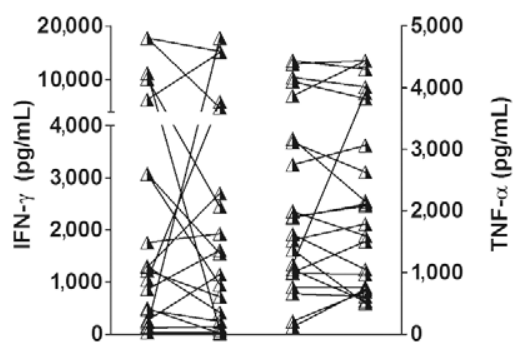

$\mathrm{F}$

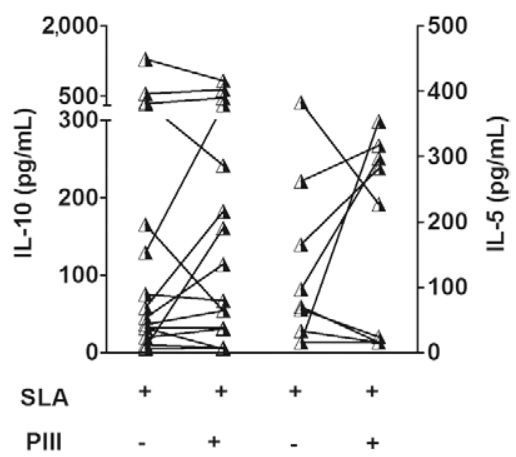

Fig. 1: levels of interferon gamma (IFN- $\gamma$ ) and tumour necrosis factor-alpha (TNF- $\alpha$ ) in cultures stimulated with soluble Leishmania antigen (SLA) in the presence or absence of Schistosoma mansoni antigens Sm29 (A), SmTSP2 (B) and PIII (C). Levels of interleukin (IL)-10 and IL-5 in cultures stimulated with SLA in the presence or absence of S. mansoni antigens Sm29 (D), SmTSP-2 (E) and PIII (F). Cytokines were measured using enzyme linked immunosorbent assay sandwich technique. Asterisk means $p<0.0005$. SLA vs. SLA + Sm29 (Wilcoxon matched pairs test).

Additionally, we assessed IL-5 production and found no significant differences between the mean levels of this cytokine detected in the supernatants of PBMC cultures stimulated with SLA alone (mean $\pm \mathrm{SEM}=66.4 \pm 23 \mathrm{pg}$ / $\mathrm{mL}$ ) or SLA plus $S$. mansoni antigens rSm29, SmTSP-2 and PIII $(62.5 \pm 22.3 \mathrm{pg} / \mathrm{mL}, 56.7 \pm 20.3 \mathrm{pg} / \mathrm{mL}$ and 89.7 $\pm 29.4 \mathrm{pg} / \mathrm{mL}$, respectively, $\mathrm{p}>0.05$ ) (Fig. 1D-F).

There was, however, a group of patients who presented with reduced levels of IFN- $\gamma$ and TNF- $\alpha$ and increased levels of IL-10 and IL-5 when Sm29, SmTSP-2 and PIII were added to the cultures stimulated with SLA. The frequency of individuals with reduced IFN- $\gamma$ production as a result of the presence of Sm29, SmTSP-2 and PIII were $40.9 \%, 36.8 \%$ and $50 \%$, respectively. Reduction in TNF- $\alpha$ levels was found in $15.8 \%, 26.3 \%$ and $27.3 \%$ of CL patients when Sm29, SmTSP-2 and PIII were added to the PBMC cultures stimulated with SLA. The addition of Sm29, SmTSP-2 and PIII to the cultures resulted in increased levels of IL-10 in $68.4 \%, 52.6 \%$ and $47.4 \%$ of patients, respectively. Additionally, levels of IL-5 were increased in $21 \%, 15.8 \%$ and $26.3 \%$ of patients when Sm29, SmTSP-2 and PIII were added to the cultures stimulated with SLA.

Patients that showed varying levels of cytokine production following the addition of the S. mansoni antigens to the cultures stimulated with SLA were further analysed individually. The levels (mean \pm SEM) of IFN- $\gamma$, TNF- $\alpha$,
IL-10 and IL-5 in the supernatants of PBMC cultures stimulated with SLA in the presence or absence of Sm29, SmTSP-2 and PIII are shown in Fig. 2. The mean levels of IFN- $\gamma$ (Fig. 2A) diminished from 5,379 $\pm 1,253 \mathrm{pg} / \mathrm{mL}$ to $1,093 \pm 540.3 \mathrm{pg} / \mathrm{mL}$ (79.7\% reduction) to $1,739 \pm 920.7$ $\mathrm{pg} / \mathrm{mL}(67.7 \%$ reduction) and to $2,409 \pm 1,357 \mathrm{pg} / \mathrm{mL}$ (55.3\% reduction) in the presence of Sm29, SmTSP-2 and PIII, respectively, compared to SLA alone $(\mathrm{p}<0.05)$.

The levels of TNF- $\alpha$ (Fig. 2B) dropped from 2,090 $\pm 210.8 \mathrm{pg} / \mathrm{mL}$ in PBMC cultures stimulated with SLA to $950.9 \pm 96.1 \mathrm{pg} / \mathrm{mL}$ ( $54.5 \%$ reduction), $1,823 \pm 450.8$ $\mathrm{pg} / \mathrm{mL}(12.7 \%$ reduction) and $1,411 \pm 356 \mathrm{pg} / \mathrm{mL}(32.5 \%$ reduction) in the presence of Sm29, SmTSP-2 and PIII, respectively. On the other hand, the levels of IL-10 (Fig. 2C) increased from $156.6 \pm 46.9-693.6 \pm 204 \mathrm{pg} / \mathrm{mL}$ (342.9\% increase after addition of Sm29), to $195.7 \pm 77.9$ $\mathrm{pg} / \mathrm{mL}$ (25\% increase in response to SmTSP-2) and to $216.7 \pm 77.9 \mathrm{pg} / \mathrm{mL}$ (38.4\% increase in response to PIII) $(p<0.05)$. There was also an increase in the levels of IL-5 from $107.4 \pm 30-177.3 \pm 62.9 \mathrm{pg} / \mathrm{mL}$ ( $65 \%$ increase) to $154.7 \pm 71.2 \mathrm{pg} / \mathrm{mL}$ ( $44 \%$ increase) and to $301 \pm 16.7 \mathrm{pg} /$ $\mathrm{mL}$ (180\% increase) when Sm29, SmTSP-2 and PIII were added to the cultures, respectively $(\mathrm{p}<0.05)$ (Fig. 2D).

Correlations between the levels of the pro-inflammatory cytokines IFN- $\gamma$ and TNF- $\alpha$ with the anti-inflammatory cytokines IL-10 and IL-5 were analysed. There was a positive correlation between the levels of TNF- $\alpha$ 
A

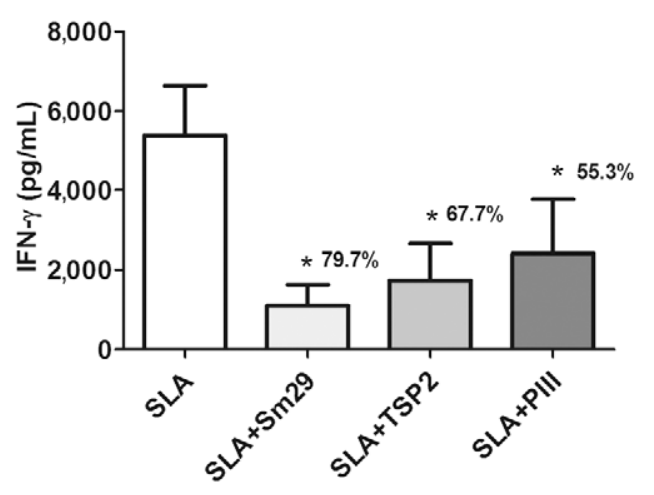

C

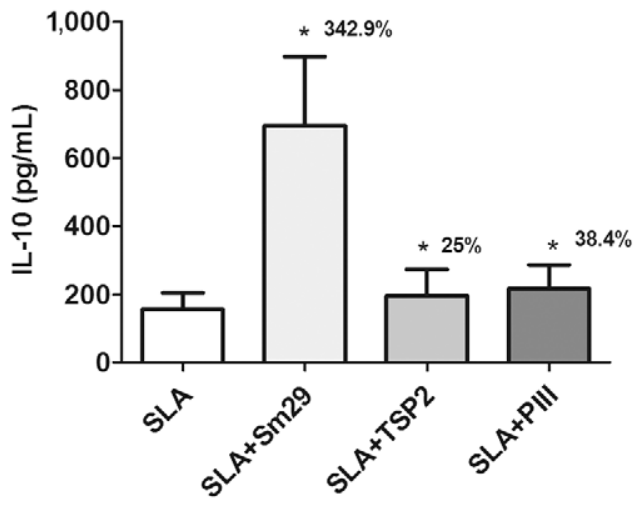

B

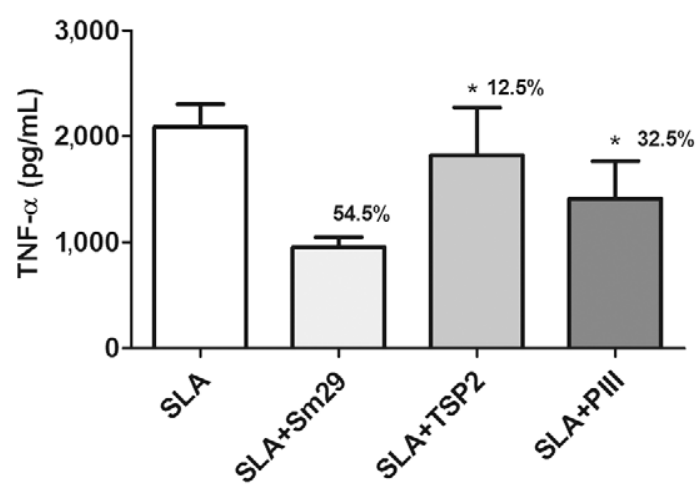

D

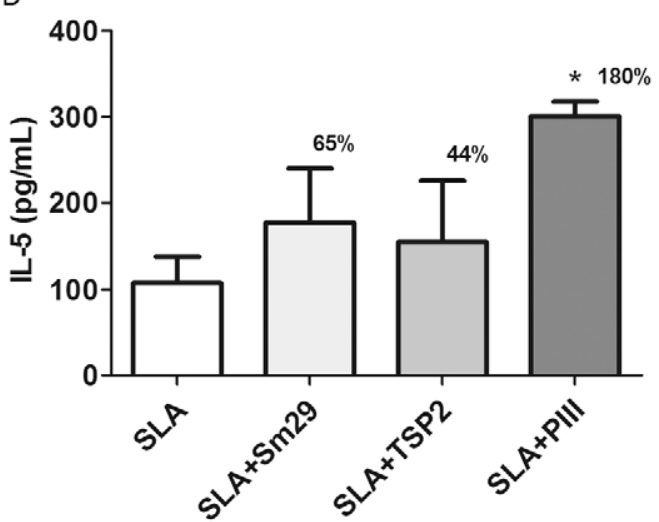

Fig. 2: levels of interferon gamma (IFN- $\gamma$ ) (A), tumour necrosis factor-alpha (TNF- $\alpha$ ) (B), interleukin (IL)-10 (C) and IL-5 (D) in peripheral blood mononuclear cells (PBMC) supernatants of cutaneous leishmaniasis patients stimulated with soluble Leishmania antigen (SLA) in vitro in the presence and absence of the Schistosoma mansoni antigens Sm29, SmTSP-2 and PIII. Cytokines were measured using enzyme linked immunosorbent assay sandwich technique. The figures represent the mean \pm standard deviation of cytokine levels in individuals who presented with decreased in the levels of IFN- $\gamma$ and TNF- $\alpha$ and increased levels of IL-10 and IL-5 when S. mansoni antigens were added to the cultures. Asterisk means $p<0.05$. SLA vs. SLA + S. mansoni antigens (Wilcoxon matched pairs test) (the percentage of reduction is indicated next to the asterisk).

and IL-5 when Sm29 $(r=0.6 ; p=0.004)$ and SmTSP2 $(r=$ $0.5 ; \mathrm{p}=0.004$ ) were added to the cultures. No significant correlation was observed between levels of IFN- $\gamma$ and IL-5 or IFN- $\gamma$ and IL-10. Additionally, there was no correlation between the levels of TNF- $\alpha$ and IL-10 when the $S$. mansoni antigens were added to the cultures (not shown).

In order to evaluate if the severity of leishmaniasis, measured by number and size of lesions, interferes with the response to $S$. mansoni antigens in vitro, we analysed the frequency of CL patients who presented or did not present reduction in the levels of IFN- $\gamma$ and TNF- $\alpha$ according to these specified parameters (Tables II, III). Patients whose levels of IFN- $\gamma$ were unaffected by the addition of SmTSP-2 to the cultures had smaller lesion size compared to patients who had reduced levels of IFN- $\gamma$ ( $p$ $<0.05$ ) (Table II). There was no significant difference in other assessed clinical parameters, such as number of lesions and number of pentavalent antimony $\mathrm{Sb}^{(\mathrm{v})}$ courses, between these two groups of patients when $S$. mansoni antigens were added to the PBMC cultures.

Additionally, patients who either had reduced levels of IFN- $\gamma$ and TNF- $\alpha$ or not when S. mansoni antigens were added to the cultures were evaluated regarding the levels of IL-10 and IL-5. Patients with reduced IFN- $\gamma$ production as a result of the addition of S. mansoni antigens and those patients in whom IFN- $\gamma$ production was unaffected had similar frequencies of individuals who displayed increased levels of IL-10 and IL-5 in response to $S$. mansoni antigens $(\mathrm{p}>0.05)$ (Table II).

The frequency of patients who had increased levels of IL-10 and IL-5 when the S. mansoni antigens were added to the cultures did not differ between the group of patients who either had a reduction in TNF- $\alpha$ production or not in the presence of $S$. mansoni antigens $(p>0.05)$ (Table III).

Finally, we compared the levels of IFN- $\gamma$ and TNF- $\alpha$ in response to SLA between the group of patients who had reduced levels of these cytokines by the addition of $S$. mansoni to the cultures and those who did not have reduced cytokine production. The levels of TNF- $\alpha$ were similar between groups $(p>0.05)$ (Table III). However, the levels of IFN- $\gamma$ were higher in patients who had reduced IFN- $\gamma$ production in response to PIII $(6,046 \pm$ $6,925 \mathrm{pg} / \mathrm{mL}$ ) as compared to those who did not have reduced production of IFN- $\gamma$ when PIII was added to the culture $(1,176 \pm 1,877 \mathrm{pg} / \mathrm{mL}, \mathrm{p}=0.05)$. 
TABLE II

Frequency of individuals who presented reduction in the levels of interferon gamma (IFN- $\gamma$ ) by the presence of Schistosoma mansoni antigens in culture stimulated with soluble Leishmania antigen (SLA) according to clinical and immunological features

\begin{tabular}{|c|c|c|c|c|c|c|}
\hline & \multicolumn{3}{|c|}{$\begin{array}{l}\text { Patients who presented } \\
\text { inhibition in IFN- } \gamma \text { production }\end{array}$} & \multicolumn{3}{|c|}{$\begin{array}{l}\text { Patients who did not present } \\
\text { inhibition in IFN- } \gamma \text { production }\end{array}$} \\
\hline & $\operatorname{Sm} 29$ & SmTSP-2 & PIII & $\operatorname{Sm} 29$ & SmTSP-2 & PIII \\
\hline \multicolumn{7}{|l|}{ Lesions $[\mathrm{n}(\%)]$} \\
\hline 1 & 7/9 (77.9) & $5 / 7(71.4)$ & 7/11 (63.6) & $10 / 13(76.9)$ & 11/12 (91.7) & 9/10 (90) \\
\hline$\geq 2$ & $2 / 9(22.2)$ & 2/7 (28.6) & 4/11 (36.4) & $3 / 13(23.1)$ & $1 / 12(8.3)$ & $1 / 10(10)$ \\
\hline \multicolumn{7}{|l|}{ Lesions size $\left(\mathrm{mm}^{2}\right)$} \\
\hline $0-99$ & 4/9 (44.5) & $3 / 7(42.9)$ & 7/11 (63.6) & $6 / 13(46.1)$ & $11 / 12(91.7)^{a}$ & $5 / 10(50)$ \\
\hline$\geq 100$ & $5 / 9(55.6)$ & 4/7 (57.1) & 4/11 (36.4) & $6 / 13(46.1)$ & 1/12 (8.3) & $4 / 10(40)$ \\
\hline No data & $0(0)$ & $0(0)$ & $0(0)$ & $1 / 13(7.7)$ & $0(0)$ & $1 / 10(10)$ \\
\hline \multicolumn{7}{|l|}{$\mathrm{Sb}^{(\mathrm{v})}$ courses $[\mathrm{n}(\%)]$} \\
\hline 1 & $2 / 9(22.2)$ & 2/7 (28.6) & $3 / 11(27.3)$ & 3/13 (23.1) & $3 / 12(25)$ & $2 / 10(20)$ \\
\hline$\geq 2$ & $5 / 9(55.6)$ & $1 / 7(14.3)$ & $5 / 11(45.5)$ & $3 / 13(23.1)$ & 4/12 (33.3) & $2 / 10(20)$ \\
\hline No data & 7/9 (77.9) & $5 / 7(71.4)$ & 7/11 (63.6) & 10/13 (76.9) & 11/12 (91.7) & $9 / 10(90)$ \\
\hline $\begin{array}{l}\text { IFN- } \gamma \text { levels in } \\
\text { response to SLA (pg/mL) }\end{array}$ & $3,766 \pm 6,154$ & $4,353 \pm 4,426$ & $6,046 \pm 6,925^{a}$ & $3,430 \pm 5,351$ & $3,852 \pm 6,722$ & $1,176 \pm 1,877$ \\
\hline \multicolumn{7}{|l|}{ Cytokines } \\
\hline Increase in IL-10 & $5 / 6(83.3)$ & $3 / 7(42.8)$ & $4 / 8(50)$ & $8 / 13(61.5)$ & $7 / 12(58.3)$ & $4 / 10(40)$ \\
\hline Increase in IL-5 & $1 / 6(16.7)$ & $1 / 7(14.3)$ & $1 / 8(12.5)$ & $3 / 13(23)$ & $2 / 12(16.7)$ & $3 / 10(30)$ \\
\hline
\end{tabular}

$a$ : patients who presented inhibition of IFN- $\gamma$ production vs. patients who did not reduce the levels of this cytokine when SmTSP-2 and PIII was added to the culture ( $\mathrm{p}<0.05$; Fisher's exact test); IL: interleukin; $\mathrm{Sb}^{(\mathrm{v})}$ : pentavalent antimony.

\section{TABLE III}

Frequency of individuals who presented reduction in the levels of tumour necrosis factor-alpha (TNF- $\alpha$ ) by the presence of Schistosoma mansoni antigens in culture stimulated with soluble Leishmania antigen (SLA) according to clinical and immunological features

\begin{tabular}{|c|c|c|c|c|c|c|}
\hline & \multicolumn{3}{|c|}{$\begin{array}{l}\text { Patients who presented } \\
\text { inhibition in IFN- } \alpha \text { production }\end{array}$} & \multicolumn{3}{|c|}{$\begin{array}{l}\text { Patients who did not present } \\
\text { inhibition in IFN- } \alpha \text { production }\end{array}$} \\
\hline & $\operatorname{Sm} 29$ & SmTSP-2 & PIII & $\operatorname{Sm} 29$ & SmTSP-2 & PIII \\
\hline \multicolumn{7}{|l|}{ Lesions [n (\%)] } \\
\hline 1 & $3 / 3(100)$ & $4 / 5(80)$ & 4/6 (66.6) & $13 / 16(81.3)$ & $12 / 14(85.7)$ & $12 / 16(75)$ \\
\hline$\geq 2$ & $0 / 3(0)$ & $1 / 5(20)$ & $1 / 6(16.7)$ & $3 / 16(18.8)$ & 2/14 (14.3) & $2 / 16(12.5)$ \\
\hline No data & $0 / 3(0)$ & $0 / 5(0)$ & $1 / 6(16.7)$ & $0 / 16(0)$ & 0/14 (0) & $2 / 16(12.5)$ \\
\hline \multicolumn{7}{|l|}{ Lesions size $\left(\mathrm{mm}^{2}\right)$} \\
\hline $0-99$ & $2 / 3(66.7)$ & $2 / 5(40)$ & $1 / 6(16.7)$ & $7 / 16(43.8)$ & $8 / 14(57.1)$ & $6 / 16(37.5)$ \\
\hline$\geq 100$ & $1 / 3(33.3)$ & $3 / 5(60)$ & 4/6 (66.6) & $8 / 16(50)$ & $5 / 14(35.7)$ & $7 / 16(43.8)$ \\
\hline No data & $0 / 3(0)$ & $0 / 5(0)$ & $1 / 6(16.7)$ & $1 / 16(6.3)$ & $1 / 14(7.1)$ & 3/16 (18.8) \\
\hline \multicolumn{7}{|l|}{$\mathrm{Sb}^{(v)}$ courses $[\mathrm{n}(\%)]$} \\
\hline 1 & $1 / 3(33.3)$ & $3 / 5(60)$ & $1 / 6(16.7)$ & $8 / 16(50)$ & 6/14 (42.9) & 3/16 (18.8) \\
\hline$\geq 2$ & $1 / 3(33.3)$ & $2 / 5(40)$ & $2 / 6(33.3)$ & $4 / 16(25)$ & 3/14 (21.4) & $7 / 16(43.8)$ \\
\hline No data & $1 / 3(33.3)$ & $0 / 5(0)$ & $2 / 6(33.3)$ & $4 / 16(25)$ & $5 / 14(35.7)$ & $6 / 16(37.5)$ \\
\hline $\begin{array}{l}\text { TNF- } \alpha \text { levels in } \\
\text { response to SLA }(\mathrm{pg} / \mathrm{mL})\end{array}$ & $1,678 \pm 188.4$ & $2,168 \pm 947.2$ & $2,051 \pm 897.8$ & $2,433 \pm 1,487$ & $2,366 \pm 1,543$ & $2,119 \pm 1,585$ \\
\hline \multicolumn{7}{|l|}{ Cytokines } \\
\hline Increase in IL-10 & $3 / 3(100)$ & $2 / 5(40)$ & $1 / 5(20)$ & $10 / 16(62.5)$ & $8 / 14(57.1)$ & $8 / 14(57.1)$ \\
\hline Increase in IL-5 & $0 / 3(0)$ & $1 / 5(20)$ & $0 / 5(0)$ & $4 / 16(25)$ & $2 / 14(14.3)$ & $5 / 14(35.7)$ \\
\hline
\end{tabular}

patients who presented inhibition of TNF- $\alpha$ production vs. patients who did not reduce the levels of this cytokine when $S$. mansoni antigens were added to the culture ( $\mathrm{p}>0.05$; Fisher's exact test); IL: interleukin; $\mathrm{Sb}^{(\mathrm{v})}$ : pentavalent antimony. 


\section{DISCUSSION}

The present study evaluated the ability of $S$. mansoni antigens to down-modulate the inflammatory response to SLA in PBMC of CL patients. We showed that the addition of the S. mansoni antigens, Sm29, SmTSP-2 and PIII, to PBMC cultures of patients infected with $L$. braziliensis stimulated with SLA reduced IFN- $\gamma$ and TNF- $\alpha$; conversely, these cells produced increased levels of IL-10 as seen in a considerable number of patients.

There is evidence that Schistosoma spp infection or its products protect against the development of Th2-mediated diseases in humans and mice (Araujo et al. 2000, 2004, Medeiros et al. 2003, 2004, Pacifico et al. 2009). Moreover, in experimental studies, it has been shown that $S$. mansoni infection or its parasite products are able to down-modulate the Th1 inflammatory response that is implicated in several autoimmune diseases, such as type-I diabetes, encephalomyelitis and psoriasis (Cooke et al. 1999, Sewell et al. 2003, Atochina \& Harn 2006).

Our group has performed studies in an attempt to identify $S$. mansoni antigens with regulatory properties that may enable them to down-regulate inflammation associated with particular immune-mediated diseases. For instance, in experimental models of OVA-induced asthma, the injection of Sm22.6, PIII or Sm29 antigens resulted in a decrease in Th2-inflammatory mediators involved with disease pathology (Cardoso et al. 2010).

Mechanisms underlying this modulation appear to include regulatory pathways induced by $S$. mansoni or their products. Indeed, it has been shown that during chronic $S$. mansoni infection, innate immune cells, T cells and T regulatory cells are able to produce IL-10 (Araujo et al. 2004, Hesse et al. 2004, Oliveira et al. 2009).

It has been demonstrated that $S$. mansoni phosphatidilserine (PS) has the ability to stimulate antigen-presenting cells from naïve individuals to produce IL-10 via Toll-like receptor-2 stimulation which promotes T-regulatory cell maturation (van der Kleij et al. 2002). Moreover, it has been demonstrated that the immune response to the Schistosoma haematobium Toll-like ligand antigen, lyso-PS, results in the production of IL-10 by cells of the innate immune system in non-infected children (van der Kleij et al. 2004). This suggests that there are molecular patterns associated with helminths that are involved in the down-regulation of the immune response.

There is evidence that an exacerbated Thl immune response with high production of IFN- $\gamma$ and TNF- $\alpha$, as well a lack of regulatory response, is associated with lesion development in CL and mucosal leishmaniasis, as reviewed by Ribeiro-de-Jesus et al. (2008). On the other hand, these cytokines are fundamental to parasite killing (Liew et al. 1990). IL-10, on the other hand, is able to control the exacerbated Th1 inflammatory response, despite data that show it could be responsible for parasite maintenance (Belkaid et al. 2001). An equilibrate immune response may be the key to a harmless hostparasite relationship.

Studies of patients with concurrent infections of $L$. braziliensis and a helminth infection have shown that these patients tend to present with smaller ulcers than patients without helminth infections. However, the time for the lesion to heal was approximately double in coinfected patients (O'Neal et al. 2007). The authors postulate that these effects are due to a stronger Th2-immune response induced by the helminth infection, which adversely affects the Th1 immune response, which compromises host defence against Leishmania sp. infection. However, another study demonstrated that early introduction of anti-helminthic therapy did not improve clinical outcomes in patients co-infected with helminths and L. braziliensis (Newlove et al. 2011).

The antigens used in this study were selected because they are secreted by the membrane and/or tegument of the $S$. mansoni adult worm. Proteins secreted or localised on the surface of Schistosoma spp, which are in intimate contact with host tissues, can be more effective at triggering immunoregulatory processes (Simpson et al. 1990). Our hypothesis is that these antigens may reduce the Th1 response by a mechanism involving regulatory cells and cytokines, rather than a shift towards a Th2 immune response.

Since there is limited production of IL-10 in CL (Bacellar et al. 2002), the use of $S$. mansoni antigens capable of inducing IL-10 production should be of benefit to these patients. Our findings show that the $S$. mansoni antigens, SmTSP-2 and PIII, were able to reduce IFN- $\gamma$ and TNF- $\alpha$ production. However, there was not a large increase in the levels of IL-10. These results suggest that IL-10 production is not the only mechanism involved in down-modulation of the inflammatory response to Leishmania infection.

Although cells from patients with CL might produce IFN- $\gamma$ and TNF- $\alpha$ to delay the infection, the modulation of these cytokines at the site of the lesion appears to be a rational strategy to limit the local exacerbated immune response.

In the conventional treatment with $\mathrm{Sb}^{(\mathrm{v})}$ there is a prolonged healing time of three-four months. This treatment has serious side effects including pancreatitis, liver enzyme abnormalities and cardiac arrhythmia (Berman 1997). The association of immunomodulators, such as granulocyte/macrophage colony stimulating factor locally applied as adjuvant therapy in low doses, improves the healing of chronic ulcers (Jaschke et al. 1999). Other drugs, such as pentoxifylline, inhibit TNF- $\alpha$ synthesis and thus down-modulates the immune response when associated with antimony therapy. This results in an increased cure rate and a decreased healing time of CL and mucosal leishmaniasis (Lessa et al. 2001, Machado et al. 2007). Therefore, the combination of conventional treatment with an immunomodulatory strategy may be more efficient in preventing or diminishing the tissue damage in CL or mucosal leishmaniasis.

In this study, we observed that patients who had reduced production of IFN- $\gamma$ in the presence of the $S$. mansoni antigens, Sm29 and PIII, show no differences in clinical parameters, such as number and size of lesion. Additionally, there was no difference in the course number of antimony therapy compared to those patients who did not have reduced levels of IFN- $\gamma$. Patients who did not have reduced IFN- $\gamma$ production in the presence 
of SmTSP-2 had smaller sized lesions compared to those who had reduced IFN- $\gamma$ production in the presence of this antigen. Nevertheless, there was no significant difference in the clinical parameters when we compared patients with reduced TNF- $\alpha$ production in the presence of the S. mansoni antigens and those who did not have reduced TNF- $\alpha$ production.

Additionally, we compared the frequency of patients who had increased levels of IL-10 and IL-5 when $S$. mansoni antigens were added to the cultures in the groups of patients who either had reduced production of IFN- $\gamma$ and TNF- $\alpha$ or production was unaffected when cultured with $S$. mansoni antigens. We found no significant difference between them. These findings indicate that even though $S$. mansoni antigens are capable of inducing Th2 and T regulatory cytokine production, other regulatory mechanisms may have a role in the down-modulation of Th1-inflammatory response in CL. Alternatively, IL-10 might be essential but not sufficient to regulate IFN- $\gamma$ and TNF- $\alpha$ production. This concept has been demonstrated where expression of IL-10 receptor was impaired in mucosal leishmaniasis (Faria et al. 2005). This could explain the results in our study where IL-10 did not down-regulate T cell responses in cells isolated from CL patients.

It has been shown that inhibition of IFN- $\gamma$ production tends to be greater at lower concentrations of this cytokine (Ito et al. 1999). In our study, the base levels of IFN- $\gamma$ in response to SLA were compared between the group of patients who had reduced IFN- $\gamma$ production with the addition of $S$. mansoni antigens to the cultures and those patients whose IFN- $\gamma$ production was unaffected. No significant differences were found in the mean levels of IFN- $\gamma$ in response to SLA in patients who had reduced levels of IFN- $\gamma$ with the addition of Sm29 and SmTSP-2 compared to the group who did not have reduced levels of IFN- $\gamma$. Unexpectedly, the base levels of IFN- $\gamma$ were higher in patients who had reduced levels of IFN- $\gamma$ with the addition of PIII compared to the group who did not have reduced levels of IFN- $\gamma$. The mean levels of TNF- $\alpha$ in response to SLA did not differ between patients based on the levels of expression of TNF- $\alpha$ that followed the addition of $S$. mansoni antigens. These data lead us to conclude that the base levels of pro-inflammatory cytokines exert little or no influence on the immune response to bystander antigens in CL.

Taken together, we have shown that the $S$. mansoni antigens Sm29, SmTSP-2 and PIII induce IL-10 and IL-5 production in CL. Additionally, these antigens are able to control the in vitro inflammatory response in patients independent of the clinical features of disease, such as number and size of lesions. Ongoing studies are being conducted to identify other regulatory mechanisms that may be involved in the down-modulation of the inflammatory response in CL.

\section{ACKNOWLEDGEMENTS}

To Dr Alfredo Goes, for his support in the development of this work, to Michael Sundberg, for his review of the manuscript, and to Dr Luiz Henrique Guimarães, Dr Paulo Machado and Ednaldo Lago, for their assistance in the endemic area.

\section{REFERENCES}

Araujo MI, Hoppe B, Medeiros M Jr, Alcantara L, Almeida MC, Schriefer A, Oliveira RR, Kruschewsky R, Figueiredo JP, Cruz AA, Carvalho EM 2004. Impaired T helper 2 response to aeroallergen in helminth-infected patients with asthma. J Infect Dis 190: 1797-1803.

Araujo MI, Lopes AA, Medeiros M, Cruz AA, Sousa-Atta L, Sole D, Carvalho EM 2000. Inverse association between skin response to aeroallergens and Schistosoma mansoni infection. Int Arch Allergy Immunol 123: 145-148.

Atochina O, Harn D 2006. Prevention of psoriasis-like lesions development in fsn/fsn mice by helminth glycans. Exp Dermatol 15: 461-468.

Bacellar O, Lessa H, Schriefer A, Machado P, Ribeiro de Jesus A, Dutra WO, Gollob KJ, Carvalho EM 2002. Up-regulation of Th1type responses in mucosal leishmaniasis patients. Infect Immun 70: 6734-6740

Belkaid Y, Hoffmann KF, Mendez S, Kamhawi S, Udey MC, Wynn TA, Sacks DL 2001. The role of interleukin (IL)-10 in the persistence of Leishmania major in the skin after healing and the therapeutic potential of anti-IL-10 receptor antibody for sterile cure. J Exp Med 194: 1497-1506.

Berman JD 1997. Human leishmaniasis: clinical, diagnostic and chemotherapeutic developments in the last 10 years. Clin Infect Dis 24: 684-703.

Bogdan C, Gessner A, Solbach W, Rollinghoff M 1996. Invasion, control and persistence of Leishmania parasites. Curr Opin Immunol 8: 517-525.

Cardoso LS, Araujo MI, Goes AM, Pacifico LG, Oliveira RR, Oliveira SC 2007. Polymyxin B as inhibitor of LPS contamination of Schistosoma mansoni recombinant proteins in human cytokine analysis. Microb Cell Fact 6: 1.

Cardoso LS, Oliveira SC, Goes AM, Oliveira RR, Pacifico LG, Marinho FV, Fonseca CT, Cardoso FC, Carvalho EM, Araujo MI 2010. Schistosoma mansoni antigens modulate the allergic response in a murine model of ovalbumin-induced airway inflammation. Clin Exp Immunol 160: 266-274.

Cardoso LS, Oliveira SC, Pacífico LG, Góes AM, Oliveira RR, Fonseca CT, Carvalho EM, Araújo MI 2006. Schistosoma mansoni antigen-driven interleukin-10 production in infected asthmatic individuals. Mem Inst Oswaldo Cruz 101 (Suppl. I): 339-343.

Cooke A, Tonks P, Jones FM, O'Shea H, Hutchings P, Fulford AJ, Dunne DW 1999. Infection with Schistosoma mansoni prevents insulin dependent diabetes mellitus in non-obese diabetic mice. Parasite Immunol 21: 169-176.

Cooper PJ, Chico ME, Rodrigues LC, Ordonez M, Strachan D, Griffin GE, Nutman TB 2003. Reduced risk of atopy among schoolage children infected with geohelminth parasites in a rural area of the tropics. J Allergy Clin Immunol 111: 995-1000.

Desjeux P 2001. The increase in risk factors for leishmaniasis worldwide. Trans R Soc Trop Med Hyg 95: 239-243.

Faria DR, Gollob KJ, Barbosa J Jr, Schriefer A, Machado PR, Lessa H, Carvalho LP, Romano-Silva MA, de Jesus AR, Carvalho EM, Dutra WO 2005. Decreased in situ expression of interleukin-10 receptor is correlated with the exacerbated inflammatory and cytotoxic responses observed in mucosal leishmaniasis. Infect Immun 73: 7853-7859.

Hesse M, Piccirillo CA, Belkaid Y, Prufer J, Mentink-Kane M, Leusink M, Cheever AW, Shevach EM, Wynn TA 2004. The pathogenesis of schistosomiasis is controlled by cooperating IL-10-producing innate effector and regulatory T cells. J Immunol 172: 3157-3166. 
Ito S, Ansari P, Sakatsume M, Dickensheets H, Vazquez N, Donnelly RP, Larner AC, Finbloom DS 1999. Interleukin-10 inhibits expression of both interferon alpha- and interferon gamma-induced genes by suppressing tyrosine phosphorylation of STAT1. Blood 93: 1456-1463.

Jaschke E, Zabernigg A, Gattringer C 1999. Recombinant human granulocyte-macrophage colony-stimulating factor applied locally in low doses enhances healing and prevents recurrence of chronic venous ulcers. Int J Dermatol 38: 380-386.

Jones TC, Johnson WD Jr., Barretto AC, Lago E, Badaro R, Cerf B, Reed SG, Netto EM, Tada MS, Franca TF, Wiese K, Gollgthtly, Fikrig F, Costa JML, Cuba CC, Marsden PD 1987. Epidemiology of American cutaneous leishmaniasis due to Leishmania braziliensis braziliensis. J Infect Dis 156: 73-83.

Lessa HA, Machado P, Lima F, Cruz AA, Bacellar O, Guerreiro J, Carvalho EM 2001. Successful treatment of refractory mucosal leishmaniasis with pentoxifylline plus antimony. Am J Trop Med Hyg 65: 87-89.

Liew FY, Li Y, Millott S 1990. Tumor necrosis factor-alpha synergizes with IFN-gamma in mediating killing of Leishmania major through the induction of nitric oxide. J Immunol 145: 4306-4310.

Machado PR, Lessa H, Lessa M, Guimaraes LH, Bang H, Ho JL, Carvalho EM 2007. Oral pentoxifylline combined with pentavalent antimony: a randomized trial for mucosal leishmaniasis. Clin Infect Dis 44: 788-793.

Medeiros M Jr., Almeida MC, Figueiredo JP, Atta AM, Mendes CM, Araujo MI, Taketomi EA, Terra SA, Silva DA, Carvalho EM 2004. Low frequency of positive skin tests in asthmatic patients infected with Schistosoma mansoni exposed to high levels of mite allergens. Pediatr Allergy Immunol 15: 142-147.

Medeiros M Jr., Figueiredo JP, Almeida MC, Matos MA, Araujo MI, Cruz AA, Atta AM, Rego MA, de Jesus AR, Taketomi EA, Carvalho EM 2003. Schistosoma mansoni infection is associated with a reduced course of asthma. J Allergy Clin Immunol 111: 947-951.

Murray HW, Cartelli DM 1983. Killing of intracellular Leishmania donovani by human mononuclear phagocytes. Evidence for oxygen-dependent and -independent leishmanicidal activity. $J$ Clin Invest 72: 32-44.

Murray HW, Rubin BY, Rothermel CD 1983. Killing of intracellular Leishmania donovani by lymphokine-stimulated human mononuclear phagocytes. Evidence that interferon-gamma is the activating lymphokine. $J$ Clin Invest 72: 1506-1510.

Newlove T, Guimaraes LH, Morgan DJ, Alcantara L, Glesby MJ, Carvalho EM, Machado PR 2011. Antihelminthic therapy and antimony in cutaneous leishmaniasis: a randomized, double-blind, placebo-controlled trial in patients co-infected with helminths and Leishmania braziliensis. Am J Trop Med Hyg 84: 551-555.

Oliveira RR, Gollob KJ, Figueiredo JP, Alcantara LM, Cardoso LS, Aquino CS, Campos RA, Almeida MC, Carvalho EM, Araujo MI 2009. Schistosoma mansoni infection alters co-stimulatory molecule expression and cell activation in asthma. Microbes Infect 11: 223-229.

O'Neal SE, Guimaraes LH, Machado PR, Alcantara L, Morgan DJ, Passos S, Glesby MJ, Carvalho EM 2007. Influence of helminth infections on the clinical course of and immune response to Leishmania braziliensis cutaneous leishmaniasis. J Infect Dis 195: 142-148.

Pacifico LG, Marinho FA, Fonseca CT, Barsante MM, Pinho V, Sales-Junior PA, Cardoso LS, Araujo MI, Carvalho EM, Cassali GD, Teixeira MM, Oliveira SC 2009. Schistosoma mansoni antigens modulate experimental allergic asthma in a murine model: a major role for $\mathrm{CD}^{+} \mathrm{CD}^{+} 5^{+} \mathrm{Foxp}^{+} \mathrm{T}$ cells independent of interleukin-10. Infect Immun 77: 98-107.

Ribeiro-de-Jesus A, Luna T, Pacheco de Almeida R, Machado PR, Carvalho EM 2008. Pentoxifylline down modulate in vitro $\mathrm{T}$ cell responses and attenuate pathology in Leishmania and HTLV-I infections. Int Immunopharmacol 8: 1344-1353.

Ribeiro-de-Jesus A, Almeida RP, Lessa H, Bacellar O, Carvalho EM 1998. Cytokine profile and pathology in human leishmaniasis. Braz J Med Biol Res 31: 143-148.

Rocha PN, Almeida RP, Bacellar O, de Jesus AR, Filho DC, Filho AC, Barral A, Coffman RL, Carvalho EM 1999. Down-regulation of Th1 type of response in early human American cutaneous leishmaniasis. J Infect Dis 180: 1731-1734.

Sewell D, Qing Z, Reinke E, Elliot D, Weinstock J, Sandor M, Fabry Z 2003. Immunomodulation of experimental autoimmune encephalomyelitis by helminth ova immunization. Int Immunol 15: 59-69.

Simpson AJ, Hagan P, Hackett F, Omer Ali P, Smithers SR 1990. Epitopes expressed on very low Mr Schistosoma mansoni adult tegumental antigens conform to a general pattern of life-cycle cross-reactivity. Parasitology 100: 73-81.

van der Kleij D, Latz E, Brouwers JF, Kruize YC, Schmitz M, KurtJones EA, Espevik T, de Jong EC, Kapsenberg ML, Golenbock DT, Tielens AG, Yazdanbakhsh M 2002. A novel host-parasite lipid cross-talk. Schistosomal lyso-phosphatidylserine activates toll-like receptor 2 and affects immune polarization. $J$ Biol Chem 277: 48122-48129.

van der Kleij D, van den Biggelaar AH, Kruize YC, Retra K, Fillie Y, Schmitz M, Kremsner PG, Tielens AG, Yazdanbakhsh M 2004. Responses to Toll-like receptor ligands in children living in areas where schistosome infections are endemic. J Infect Dis 189: 1044-1051. 